\title{
Concentration of LDLR, degree of hepatic fibrosis and hepatic steatosis in patients with chronic hepatitis B infection treated with tenofovir disoproxil fumarate
}

\author{
Agnieszka Pokora-Rodak ${ }^{1, A-C \oplus}$, Joanna Krzowska-Firych ${ }^{1, D-E \oplus}$, Krzysztof Tomasiewicz ${ }^{1, F \oplus}$ \\ ${ }^{1}$ Medical University, Lublin, Poland \\ A - Research concept and design, B - Collection and/or assembly of data, C - Data analysis and interpretation, \\ $D$ - Writing the article, E-Critical revision of the article, $F$ - Final approval of article
}

Pokora-Rodak A, Krzowska-Firych J, Tomasiewicz K. Concentration of LDLR, degree of hepatic fibrosis and hepatic steatosis in patients with chronic hepatitis B infection treated with tenofovir disoproxil fumarate. Ann Agric Environ Med. 2021; 28(3): 458-462. doi: 10.26444/aaem/122627

\begin{abstract}
Introduction. Epidemiological data indicate that one-third of the world's population have serological markers of hepatitis $B$ virus infection. Hepatic steatosis is often observed in patients with chronic liver diseases. The exact mechanisms of hepatic steatosis progression and the efficacy of antiviral therapy in patients with $\mathrm{CHB}$ and hepatic steatosis are not yet fully understood.

Objective. The aim of the study was to investigate the LDLR concentration and degree of hepatic fibrosis and hepatic steatosis in patients with chronic hepatitis B infection during tenofovir disoproxil fumarate therapy.

Materials and method. The study group consisted of 54 patients with CHB. The LDLR concentration, assessment of the degree of hepatic fibrosis, hepatic steatosis, total cholesterol, low density lipoprotein, high density lipoprotein and triglyceride concentrations, were assessed at the beginning of therapy, 6 months later, and 12 months after commencement of therapy. The control group consisted of 18 healthy individuals.

Results. The mean LDLR concentration in the studied groups was statistically significantly lower $(p<0.05)$ than in the controls. The antiviral therapy based on TDF had no influence on the LDLR concentration and HBsAg level.

Conclusions. The results indicate a statistically significant lower $(p<0.05)$ concentration of LDLR in patients with chronic hepatitis B infection. Negative correlations between HBsAg level and LDLR concentration in patients with chronic HBV, at all stages of the study may indicate, that HBsAg protects hepatocytes from LDL accumulation.
\end{abstract}

\section{Key words}

LDLR, LDL, Lipids' metabolism, HBV, Tenofovir treatment

\section{INTRODUCTION}

Patients with chronic hepatitis B virus infection (CHB) are at risk of life-threatening complications such as liver cirrhosis and primary hepatocellular carcinoma (HCC). The epidemiological data indicate that one-third of the world's population have serological markers of hepatitis B virus (HBV) infection [1]. The accumulation of fat, mainly triglycerides, within liver cells results in the development of hepatic steatosis (HS), which is often observed in patients with chronic liver diseases. The percentage of HS prevalence among patients with $\mathrm{CHB}$ ranges from $14 \%-67 \%$ [2]. The results of recently published studies indicate that hepatic steatosis is associated with the development of fibrosis in patients with hepatitis B virus infection, and also has an influence on a worse response to antiviral therapy in this group of patients $[3,4]$.

The presence of metabolic syndrome increases the risk of complications in patients with $\mathrm{CHB}$ [2]. Non-alcoholic fatty liver disease (NAFLD) is the most common cause of chronic liver disease associated with an increased risk of cirrhosis and HCC. The incidence of NAFLD in patients

Address for correspondence: Agnieszka Pokora-Rodak, Medical University, Lublin, Poland

E-mail: agniecha811@gmail.com

Received: 06.04.2020; accepted: 18.05.2020; first published: 10.06.2020 with chronic hepatitis $\mathrm{B}$ infection is estimated to be between $6 \%$ - 33\%. Recently published data showed an inverse relationship between $\mathrm{HBV}$ infection and metabolic syndrome [5, 6]. Meta-analysis revealed that hepatitis B virus infection decreases the risk of NAFLD development $[7,8]$. There are also data indicating that the $\mathrm{X}$ protein of hepatitis $B$ virus inhibitsthe release of apolipoprotein $B$, which plays an important role in the synthesis of both very low-density and low-density lipoproteins [9]. The association between low serum concentration of total cholesterol (TC) and infection with HBV has been noted [10]. The exact mechanisms of hepatic steatosis progression and the efficacy of antiviral therapy in patients with $\mathrm{CHB}$ and hepatic steatosis are not fully understood [6]. It is estimated that around $67 \%$ of the serum cholesterol is transported to organs such as muscles or adipose tissue by low-density lipoprotein (LDL). The mature low-density lipoprotein receptor (LDLR) is a transmembrane protein type I which plays an important role in the cholesterol concentration in human cells. The plasma LDL concentration is upregulated by its liver receptor which is responsible for the binding and internalization of LDL-cholesterol. The uptake of LDL by hepatocytes depends on the activity of LDLR. Differences in plasma LDL concentration are the result of changes in receptor activity. The results of recently published data indicate that hepatitis B virus increases the expression of cholesterol metabolism related genes [11]. The replication 
of HBV in the liver is considered an important risk factor for liver damage, and the viral load correlates with an increased risk with the development of cirrhosis and HCC.

The main goal of antiviral therapy for patients with $\mathrm{CHB}$ infection is to prevent progression of the disease which increases survival and improves the quality of life. It is also important to prevent $\mathrm{HBV}$ reactivation and transmission to others. Results of long-term studies show that the maximal and sustained suppression of viral replication to undetectable levels reverts liver fibrosis and necroinflammatory activity in most patients. Currently, two classes of antiviral drugs are available for the therapy of HBV. Immune modulators, such as interferon $\alpha$ and nucleoside or nucleotide analogues (NA), act as reverse transcriptase inhibitors of the HBV polymerase. Tenofovir disoproxil fumarate (TDF) is a potent antiviral drug with confirmed activity against the wild type, and also lamivudine-resistant HBV strains with good safety profile. According to guidelines, it is recommended as the first-line therapy for patients with CHB. Marcellin, et al. demonstrated the efficacy of TDF in reducing the severity of liver fibrosis and cirrhosis during therapy $[12,13]$. Genotypic resistance, however, has not been described. The results of long-term therapy with TDF in HBs-Ag negative patients show that the rates of virological response ranged from $92 \%$ - 100\%, with no evidence of resistance. In the study group, $75 \%$ of patients achieved biochemical response, defined as the normalization of the aminotransferases activity [14].

\section{OBJECTIVE}

The aim of the study was to investigate the LDLR concentration, the degree of hepatic fibrosis and hepatic steatosis in patients with chronic hepatitis B infection during tenofovir disoproxil fumarate - based antiviral therapy. The concentration was also assessed of total cholesterol, triglycerides, high and low density lipoproteins, and the qHBSAg and HBV DNA level.

\section{MATERIALS AND METHOD}

The study group consisted of 54 individuals with chronic hepatitis B infection, treated with tenofovir disoproxil fumarate in the XXXX. TDF was administered according to the guideline recommendations. Chronic hepatitis is defined as the persistence of hepatitis B surface antigen for longer than six months. In all subjects, $\mathrm{HBe}$-antigen was negative. Patients with chronic hepatitis $\mathrm{C}$ infection and human immunodeficiency virus co-infection were excluded from the study. The control group consisted of 18 healthy volunteers: 10 male patients and 8 females, aged $36-58$ years (mean age 46.3 years). All patients from the study group were negative for HBV, HCV, and HIV. The LDL-receptor concentration, assessment of the degree of hepatic fibrosis, hepatic steatosis, total cholesterol, LDL, HDL and TG concentrations were assessed at the beginning of therapy (Group 1), 24 weeks after the beginning of therapy (Group 2), and 48 weeks after the start of therapy (group 3). Quantification of HBsAg (qHBsAg) was determined 3 times, at the beginning of therapy and at 24-week intervals.

The viral load was assessed in Group 1 and in Group 3, respectively, using the Cobas $^{\circledast}$ Ampli Prep/ COBAS TaqMan ${ }^{\circledast} \mathrm{HBV}$ Test v 2.0 developed by Roche. The LDLR concentration was determined using an ELISA-kit (Shanghai Sunred Biological Technology Co., Ltd., Shanghai, China). Hepatic fibrosis was measured by applying the transient elastography method using the FibroScan device. The measurement range was $2.5-75 \mathrm{kPa}$

(Metavir fibrosis score: F0/F1 < 5\% corresponding to $180-220 \mathrm{~dB} / \mathrm{m}$, steatosis S1 5-33\%: $250 \mathrm{~dB} / \mathrm{m}-300 \mathrm{~dB} / \mathrm{m}$, steatosis S2 34-66\%: $280 \mathrm{~dB} / \mathrm{m}-350 \mathrm{~dB} / \mathrm{m})$. Determination of HBsAg was performed using the Elecsys system manufactured by Roche, using an analyzer for standard immunochemical determinations and the Cobas e 411 Electrochemiluminescence (ECL) Technology (Roche Polska Sp z. o.o, Warsaw).

The study was approved by the Bioethical Commission of the Medical University in Lublin, and written informed consent was obtained from each patient before enrolment.

Statistical analyses. The MS Office 2007, Statistica 12.0. software was used for compilation of the results. Consistency of the distribution of variables with normal distribution was checked using the Shapiro-Wilk test of normality. Results are presented using basic descriptive statistics: mean value, median, standard deviation, minimum and maximum values. Comparative analysis for the variables was performed using parametric and non-parametric statistical tests. Student's parametric t-test was performed for normally distributed continuous quantitative variables by comparing the results from 2 groups. In the remaining cases, non-parametric tests were used for qualitative variables. Wilcoxon's test was applied for paired samples, while the Mann-Whitney $\mathrm{U}$ Test was used to confront 2 independent samples. The homogeneity of variances was estimated by applying the Levene's test. In order to compare the concentration of the tested parameters, the F-Test was applied in a one way analysis of variance (ANOVA).

If homogeneity was not found for dependent samples, the conservative F-test or Friedman's test was applied, as well as multiple comparison analysis, i.e. the so-called Dunn's post hoc test with Bonifferoni adjustment was used. Correlation tests were applied to assess simple correlation between individual parameters. For normally distributed continuous variables, the Pearson parametric correlation test was applied. In the remaining cases, non-parametric tests were applied, i.e. Spearman Rank Correlation. The correlations were considered statistically significant at $\mathrm{p}<0.05$.

\section{RESULTS}

In the study group, the male patients accounted for $74 \%$ (40 patients) and the female patients accounted for 26\% (14 patients). Mean age of male patients -47.8 years; females - 50.2 years. The concentration of total cholesterol, LDL, triglycerides, HDL-cholesterol in group 1, 2, 3 and in controls are presented in Table 1. The mean LDL concentration in Group 1 was $94.0 \mathrm{mg} / \mathrm{dl}$ (range 49.0-224 mg/dl) with an average value of $100.63 \pm 38.03 \mathrm{mg} / \mathrm{dl}$. In Group 2, the mean LDL concentration was $96.0 \mathrm{mg} / \mathrm{dl}$ (range 60.0-202.0), with an average value of $102.15 \pm 33,16 \mathrm{mg} / \mathrm{dl}$. In Group 3, the mean LDL concentration was $92.0 \mathrm{mg} / \mathrm{dl}$ (range 53.0 -191.0), with an average value of $101.81 \pm 37.1 \mathrm{mg} / \mathrm{dl}$. In the control group, the mean LDL concentration was $99.5 \mathrm{mg} / \mathrm{dl}$ (range 56.0$118.0 \mathrm{mg} / \mathrm{dl})$, with an average value of $96.43 \pm 18.0 \mathrm{mg} / \mathrm{dl}$. The 
Table 1. Concentration of total cholesterol, LDL, triglycerides, HDLcholesterol in group 1, 2, 3 and in controls

\begin{tabular}{lcccc}
\hline & Group 1 & Group 2 & Group 3 & Control group \\
\hline & $\bar{x} \pm$ SD & $\bar{x} \pm$ SD & $\bar{x} \pm$ SD & $\bar{x} \pm S D$ \\
& Mean & Mean & Mean & Mean \\
& Min. Max. & Min. Max. & Min. Max. & Min. Max. \\
& $n=54$ & $n=54$ & $n=54$ & $n=54$ \\
\hline Total cholesterol & $175.36 \pm 44.83$ & $180.67 \pm 37.68$ & $179.52 \pm 40.59$ & $165.0 \pm 24.13$ \\
[mg/dl] & 160.0 & 175.0 & 173.0 & 173.5 \\
& $112.6-305.0$ & $118.0-270.0$ & $119.0-266.0$ & $116.0-189.0$ \\
\hline & $55.39 \pm 15.41$ & $55.67 \pm 11.18$ & $55.67 \pm 11.18$ & $60.31 \pm 12.85$ \\
HDL [mg/dl] & 55.0 & 54.5 & 54.5 & 58.5 \\
& $34.0-90.8$ & $40.0-87.0$ & $40.0-87.0$ & $41.0-80$. \\
\hline & $100.67 \pm 44.82$ & $105.96 \pm 48.3$ & $107.85 \pm 41.67$ & $89.0 \pm 28.85$ \\
TG [mg/dl] & 84.0 & 90.0 & 92.0 & 83.0 \\
& $48.0-220.0$ & $40.0-222.0$ & $48.0-207.0$ & $46.0-141.0$ \\
\hline & $100.63 \pm 38.03$ & $102.15 \pm 33.16$ & $101.81 \pm 37.1$ & $96.43 \pm 18.0$ \\
LDL [mg/dl] & 94.0 & 96.0 & 92.0 & 99.5 \\
& $49.0-224.0$ & $60.0-202.0$ & $53.0-191.0$ & $56.0-118.0$ \\
\hline & $3.46 \pm 2.03$ & $3.67 \pm 2.16$ & $4.02 \pm 2.54$ & $26.25 \pm 4.68$ \\
& 2.86 & 2.9 & 3.0 & 26.5 \\
LDLR [ng/ml] & $1.42-9.3$ & $1.2-10.8$ & $1.53-10.0$ & $15.0-34.0$ \\
& & & &
\end{tabular}

mean LDLR concentration in Group 1 was $2.86 \mathrm{ng} / \mathrm{ml}$ (range $1.42-9.3 \mathrm{ng} / \mathrm{ml})$, with an average value of $3.46 \pm 2.03 \mathrm{ng} / \mathrm{ml}$. Twenty-four weeks after the beginning of antiviral therapy the mean concentration of LDLR was $2.9 \mathrm{ng} / \mathrm{ml}$ (range 1.2$10.8 \mathrm{ng} / \mathrm{ml}$ ), with an average value of $3.67 \pm 2.16 \mathrm{ng} / \mathrm{ml}$. In Group 3, the mean LDLR concentration was $3.0 \mathrm{ng} / \mathrm{ml}$ (range $1.53-10,0 \mathrm{ng} / \mathrm{ml}$ ) with an average value $4,02 \pm 2,54 \mathrm{ng} / \mathrm{ml}$. In the controls the mean value was $26,5 \mathrm{ng} / \mathrm{ml}$ (range 15.0-34.0 $\mathrm{ng} / \mathrm{ml})$, with an average value of $26.25 \pm 4.68 \mathrm{ng} / \mathrm{ml}$.

Assessment of hepatic fibrosis. The assessment of hepatic fibrosis in Group 1 showed that the values obtained from elastography measurements ranged from $3.8 \mathrm{kPa}-18.5 \mathrm{kPa}$ (mean value $6.3 \mathrm{kPa}$ ), with an average value of $7.42 \pm 3.61 \mathrm{kPa}$. After 6 months (Group 2), the mean value was $5.9 \mathrm{kPa}$, range $3.0-17.0 \mathrm{kPa}$, with an average value of $6.62 \pm 3.05 \mathrm{kPa}$. During the subsequent third measurement after 48 weeks of antiviral therapy, the mean fibrosis value was $4.9 \mathrm{kPa}$, range 3.5-16.8 $\mathrm{kPa}$, with an average value of $5.9 \pm 2.71 \mathrm{kPa}$ (Tab. 2)

Table 2. Hepatic fibrosis. hepatic steatosis (CAP), and HBsAg levels in the study groups

\begin{tabular}{lccc}
\hline & Group 1 & Group 2 & Group 3 \\
\hline & $\bar{x} \pm S D$ & $\bar{x} \pm S D$ & $\bar{x} \pm S D$ \\
& Mean & Mean & Mean \\
& Min. Max. & Min. Max. & Min. Max. \\
& $n=54$ & $n=54$ & $n=54$ \\
\hline & $7.42 \pm 3.61$ & $6.62 \pm 3.05$ & $5.9 \pm 2.71$ \\
Fibrosis $[\mathrm{kPa}]$ & 6.3 & 5.9 & 4.9 \\
& $3.8-18.5$ & $3.0-17.0$ & $3.5-16.8$ \\
\hline & $244.44 \pm 50.38$ & $235.11 \pm 56.46$ & $235.7 \pm 49.9$ \\
CAP $[\mathrm{db} / \mathrm{m}]$ & 233.0 & 228.0 & 220.0 \\
& $180.0-360.0$ & $100.0-370.0$ & $170.0-340.0$ \\
\hline & $20133.27 \pm 26403.93$ & $16973.18 \pm 22230.22$ & $17626.03 \pm 24266.88$ \\
HBsAg $[\mathrm{IU} / \mathrm{ml}]$ & 8156.9 & 8254.7 & 6723.6 \\
& $84.8-99571.0$ & $88.0-98811.8$ & $75.0-100185.5$ \\
\hline
\end{tabular}

Assessment of hepatic steatosis. The assessment of hepatic steatosis at the beginning of antiviral therapy showed that the results of elastography measurements of steatosis ranged from $180.0-360.0 \mathrm{~dB} / \mathrm{m}$ (mean value $233.0 \mathrm{~dB} / \mathrm{m}$ ), average value $244.44 \pm 50.38 \mathrm{~dB} / \mathrm{m}$. In Group 2, the mean value was $228.0 \mathrm{~dB} / \mathrm{m}$ (range $100.0-370.0 \mathrm{~dB} / \mathrm{m}$ ), average value $235.11 \pm 56.46 \mathrm{~dB} / \mathrm{m}$. In Group 3 , the mean value was $220.0 \mathrm{~dB} / \mathrm{m}$ (range $170.0-340.0 \mathrm{~dB} / \mathrm{m}$ ), with an average $235,7 \pm 49,9 \mathrm{~dB} / \mathrm{m}$. HBsAg level and HBV DNA concentration The mean HBsAg level in Group 1 was $8156,9 \mathrm{IU} / \mathrm{ml}$ (ranged from 84,8-99571,0 IU/ml), average value 20133.27 \pm 26403.93 $\mathrm{IU} / \mathrm{ml}$. In Group 2, the mean HBsAg concentration was $8254.7 \mathrm{IU} / \mathrm{ml}$ (range $88.0-98811.8 \mathrm{IU} / \mathrm{ml}$ ), average value $16973.18 \pm 22230.22 \mathrm{IU} / \mathrm{ml}$.

At the end of the study (Group 3), the mean HBsAg concentration was 6723.6 IU/ml (range 75.0-100185,5 IU/ $\mathrm{ml}$, average value $17626.03 \pm 24266.88 \mathrm{IU} / \mathrm{ml}$ (Tab. 2). Fortyeight weeks after the start of the study (Group 3), HBV DNA concentration was reduced to a level below $6 \mathrm{IU} / \mathrm{ml}$ in all patients. No correlation was found between HBsAg and HBV DNA concentration. There were inverse Spearman's correlations between HBsAg concentration and LDLR concentration at all stages of the study (Fig. 1-3). In the entire study group, beginning from the first test with $\mathrm{p}=0.000039$, Group 2 followed with $\mathrm{p}=0.000133$, and $\mathrm{p}=0.00024$ at the end of the study. Moreover, inverse Spearman's correlations were found between HBsAg concentrations and hepatic fibrosis at all stages of the study, in the entire study group, starting from the first measurement with $\mathrm{p}=000927$, followed by Group 2 with $\mathrm{p}=0.019$, and $\mathrm{p}=0.025$ at the end of the study.

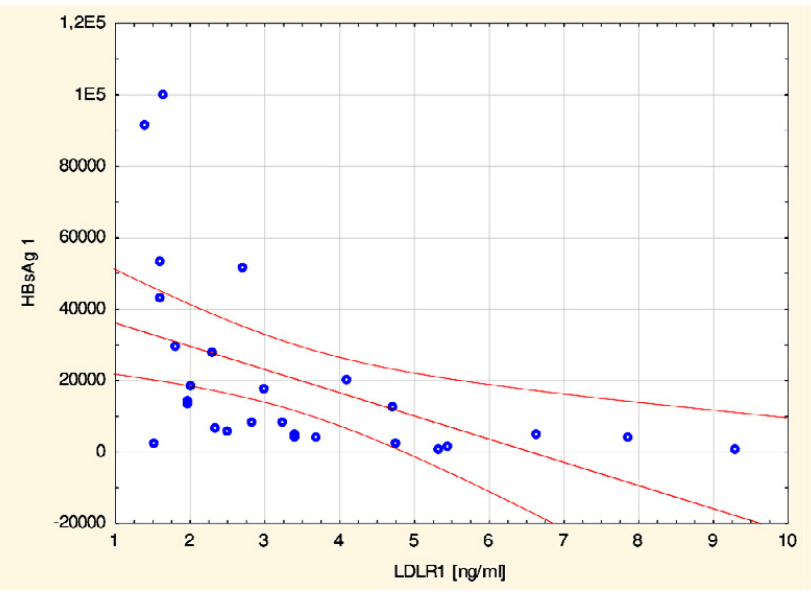

Figure 1. Sperman's correlations between HBsAg concentrations and LDLR concentrations in Group 1

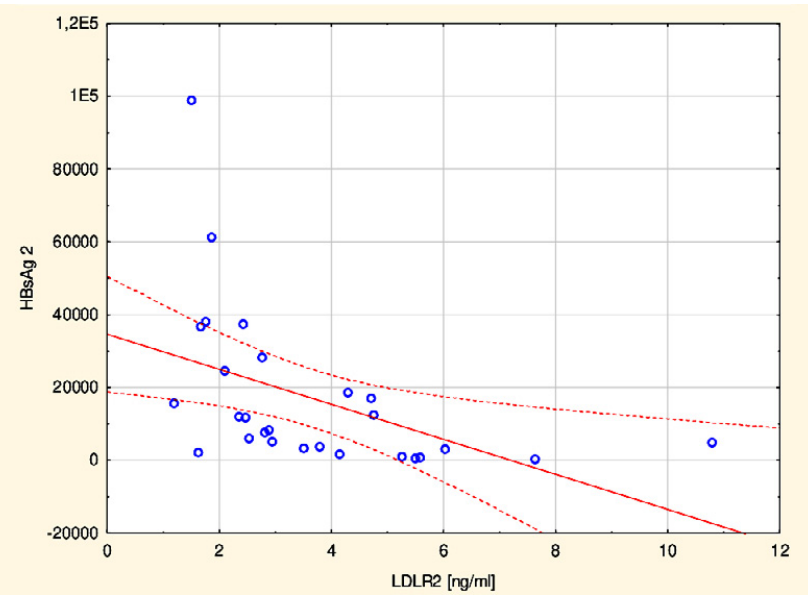

Figure 2. Sperman's correlations between HBsAg concentrations and LDLR concentrations in Group 2 


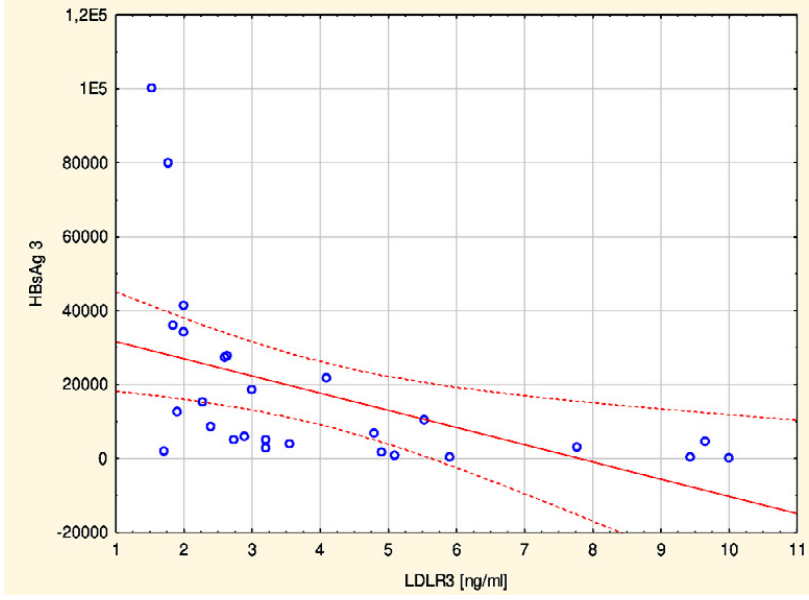

Figure 3. Sperman's correlations between HBsAg concentrations and LDLR concentrations in Group 3

A positive correlation was found between LDLR and fibrosis with $\mathrm{p}=0.0521$ in Group 1 and in Group 2.

\section{DISCUSSION}

The study reports the LDLR concentration in patients with $\mathrm{CHB}$ infection during TDF-based antiviral treatment. LDLR plays a major role in the removal of plasma LDL from the liver. In the literature, there are limited data assessing the potential influence of LDLR concentration and liver steatosis during antiviral therapy with tenofovir disoproxil fumarate. The results of the study showed significant differences in the mean LDLR concentration between the study groups and control group $(\mathrm{p}<0.05)$. An almost 6 times lower concentration of low-density lipoprotein receptor was found in the study groups, compared to the controls, which may suggest disturbances in the liver LDL uptake in patients with hepatitis $\mathrm{B}$ infection at the beginning and during antiviral treatment. The lower LDLR density was correlated with lower LDL uptake by hepatocytes. As demonstrated in many studies, the receptor of low-density lipoprotein is important in the liver as a mediator responsible for plasma LDL clearance; however, the effect of lack of receptor (LDLR) on the metabolism of hepatic lipids has not been determined. The impaired function of LDLR in humans resulted in an increase in total cholesterol concentration and accumulation of plasma lipoproteins. In humans, the occurrence of fulminant atherosclerosis as a result of a lack of receptor and an increase in plasma total cholesterol, was also observed.

Deletion of the receptor in mice does not cause atherosclerosis, due to a relatively small increase in the concentration of total cholesterol when fed with a normal diet [15]. The results from studies with animal models indicate that in the LDLR knockout rats, the liver activates the compensatory mechanisms with a significant increase in expression of key enzymes responsible for lipogenesis and cholesterol synthesis. It was also shown that deletion of LDLR influenced the liver metabolism of free fatty acids, sphingolipids, and lysophosphatidylcholines in rats [16].

It should be noted that the lower concentration of LDLR in patients from the studied groups did not affect the level of total cholesterol and its fraction. There were no significant differences in the concentration of lipid fraction investigated in the studied groups compared to the control group. The results from the current study do not reveal a correlation between LDLR level and plasma lipids concentration. Wang, et al. observed a negative correlation between hepatic steatosis and intrahepatic expression of HBsantigen in patients infected with hepatitis $B$ virus. The presence of HBs-ag in hepatocytes, confirmed by positive staining, was considered asan independent factor associated with lower risk of developing HS [17]. In Sundeep, et al. found no correlation the between the level of the ' $s$ ' antigen and the degree of liver fibrosis [18]. In the current study, the variances were homogeneous in the Levene's test for HBs-Ag levels. Results of the F-test in a one-way analysis of variance $(\mathrm{F}=0.12 ; \mathrm{p}=0.88)$ showed that the reduced antigen levels were not statistically significant in the study groups of patients during tenofovir-based antiviral therapy at various time intervals. The negative correlation between the HBsAg concentration level and LDLR at each stage of this study suggests the protective effect of the 's' antigen on the LDL accumulation in the liver hepatocytes.

In order to evaluate the effectiveness of antiviral therapy, the viral load and the amount of HBsAg (qHBsAg) were assessed. The virological response during NAs therapy is defined as the undetectable viral load assessed by polymerase chain reaction (PCR) with a detection limit of $10 \mathrm{IU} / \mathrm{ml}$. The results presented by Rastogi, et al. indicate that HBV DNA level negatively correlated with steatosis, which was observed in one-third of patients with hepatitis B infection [19]. From the results of the presented study, it appears that liver steatosis remained stable through the entire study period. No fluctuations in the degree of steatosis were found during TDF-based antiviral therapy. HS seems to worsen the prognosis of hepatic fibrosis in CHB infection [20]. Transient elastography (TE) equipped with a controlled attenuation parameter (CAP) is a technique used in assessing the degree of steatosis and fibrosis of the liver. In this study, a significant decrease in fibrosis was detected with persistent high levels of HBsAg. Results of the study did not show any correlation between fibrosis and steatosis. In the results presented by Yilmaz et al., no correlation was found between the viral load and the degree of liver steatosis [21]. Machado et al. found that hepatosteatosis was a consequence of metabolic changes and was less frequent than in patients with chronic hepatitis $\mathrm{C}$ infection. Lesmana et al. showed that liver steatosis observed in $30 \%$ of patients with chronic hepatitis $\mathrm{B}$ infection was related with central obesity $[22,23]$. Data presented by Minakari et al. indicate that HS is not related to age and gender of patients nor with $\mathrm{HBeAg}$, viral load, plasma cholesterol concentration, degree of fibrosis, or with liver enzymes [24].

\section{CONCLUSIONS}

The results of this study indicate a statistically significant lower concentration of LDLR in patients with CHB. TDFbased therapy had no influence on LDLR concentration and HBs-Ag level. The negative correlations between HBs-Ag level and LDLR concentration at all stages of the study may indicate that the ' $s$ ' antigen protects hepatocytes from lowdensity lipoprotein accumulation. 
Study limitations. The main limitation of the study is the short duration of observation (48 weeks). The tests were perfomed 3 times, at the beginning of antiviral therapy, and then at 6 months intervals. Future studies are necessary to confirm the preliminary results.

\section{REFERENCES}

1. Alter MJ. Epidemiology of hepatitis B in Europe and worldwide. J Hepatol. 2003; 39: 64-69.

2. Fan JG, Kim SU, Wong VW. New trends on obesity and NAFLD in Asia. J Hepatol. 2017; 67: 862-873.

3. Wong GL, Wong VW, Choi PC, Chan AW, Chim AM, Yiu KK, et al. Metabolic syndrome increases the risk of liver cirrhosis in chronic hepatitis B. Gut 2009; 58: 111-117.

4. Zhu Y, Yang Q, Lv F, Yu Y. The effect of hepatosteatosis on response to antiviral treatment in patients with chronic hepatitis B: a metanalysis. Gastroenterol Res Pract. 2017; 2017: 1096406.

5. Adams LA, Lymp JF, St Sauver J, Sanderson SO, Lindor KD, Feldstein A, Angulo P. The natural history of nonalcoholic fatty liver disease: a population-based cohort study. Gastroenterology. 2005; 129: 113-121.

6. Wang CC, Tseng TC, Kao JH. Hepatitis B virus infection and metabolic syndrome: fact or fiction? J Gastroenterol Hepatol. 2015; 30: 14-20.

7. Xiong J, Zhang H, Wang Y, Wang A, Bian J, Huang H, Zheng Y, Sang $\mathrm{X}, \mathrm{Xu} \mathrm{Y}, \mathrm{Lu} \mathrm{X}$ Zhao H. Hepatitis B virus infection and the risk of nonalcoholic fatty liver disease: a meta-analysis. Oncotarget. $2017 \mathrm{Nov}$ 3; 8(63): 107295-107302. doi: 10.18632/oncotarget.22364. eCollection 2017 Dec 5

8. Liu J, Yang HI, Lee MH, Lu SN, Jen CL, Wang LY, You SL, Iloeje $\mathrm{UH}$, Chen CJ. Incidence and determinants of spontaneous hepatitis B surface antigen seroclearance: a community-based follow-up study. Gastroenterology. 2010; 139: 474-482.

9. Kang SK, Chung TW, Lee JY, Lee YC, Morton RE, Kim CH. The hepatitis $\mathrm{B}$ virus $\mathrm{X}$ protein inhibits secretion of apolipoprotein $\mathrm{B}$ by enhancing the expression of Nacetylglucosaminyltransferase III. J Biol Chem. 2004; 279: 28106- 28112.

10. Chen JY, Wang JH, Lin CY, Chen PF, Tseng PL, Chen CH, Chang KC, Tsai LS, Chen SC, Lu SN. Lower prevalence of hypercholesterolemia and hyperglyceridemia found in subjects with seropositivity for both hepatitis B, C strains independently. J Gastroenterol Hepatol. 2010; 25: $1763-1768$

11. Li YJ, Zhu P, Liang Y, Yin WG, Xiao JH. Hepatitis B virus induces expression of cholesterol metabolism-related genes via TLR2 in HepG2 cells. World J Gastroenterol. 2013; 19: 2262-2269.
12. European Association for the Study of the Liver. EASL clinical practice guidelines: management of chronic hepatitis B. J Hepatol. 2009; 50: 227-242.

13. Marcellin P, Gane E, Buti M. Regression of cirrhosis during treatment with tenofovir disoproxil fumarate for chronic hepatitis B: a 5-year open-label follow-up study. Lancet 2013; 381: 468-475.

14. Clercq ED, Férir G, Kaptein S, Neyts J. Antiviral Treatment of Chronic Hepatitis B Virus (HBV) Infections Viruses. 2010 Jun; 2(6): 1279-1305.

15. Ishibashi S, Brown MS, Goldstein JL, Gerard RD, Hammer RE, Herz J. Hypercholesterolemia in low density lipoprotein receptor knockout mice and its reversal by adenovirus-mediated gene delivery. J Clin Invest. 1993; 1885-1893.

16. Hong Yu Wang, Chao Quan, Chunxiu Hu, Bingxian Xie, Yinan Du, Liang Chen, Wei Yang, Liu Yang, Qiaoli Chen, Bin Shen, et al. A lipidomics study reveals hepatic lipid signatures associating with deficiency of the LDL receptor in a rat model. Biology Open 2016; 5 : 979-986. doi:10.1242/bio.019802

17. Wang MM, Wang GS, Shen F. Hepatic steatosis is highly prevalent in hepatitis B patients and negatively associated with virological factors. Dig Dis Sci. 2014; 59: 2571-2579.

18. Sundeep K, Goyal, Ashok K Jain, Vinod K Dixit, Suneet K Shukla, Mohan Kumary, Jayant Ghosh, Arttrika Ranjan, Neha Gupta, Manish Tripathi. HBsAg Level as Predictor of Liver Fibrosis in HBeAg Positive Patients With Chronic Hepatitis B Virus Infection. J Clin Exp Hepatol. 2015; 5(3); 213-220.

19. Rastogi A, Sakhuja P, Kumar A. Steatosis in chronic hepatitis B: prevalence and correlation with biochemical, histologic, viral, and metabolic parameters. Indian J Pathol Microbiol. 2011; 54: 454-459.

20. Dogan Z, Filik L, Ergül B. Comparison of first-year results of tenofovir and entecavir treatments of nucleos(t)ide-naive chronic hepatitis B patients with hepatosteatosis. Saudi J Gastroenterol. 2015; 21: 396-399.

21. Yimaz B, Koklu S, Buyukbayram H, Yalcin K, Korkmaz U, Posul E. Chronic hepatitis B associated with hepatic steatosis, insulin resistance, necroinflammation and fibrosis. Afr Health Sci. 2015 Sep; 15(3): $714-$ 718. doi: 10.4314/ahs.v15i3.3

22. Machado MV, Oliveire AG, Cortez-Pinto H. Hepatic steatosis B virus infected patients: meta-analysis of risk factors and comparison with hepatitis C infected patients. J Gastroenterol Hepatol. 2011; 26: 13611367.

23. Lesmana LA, Lesmana CR, Pakasi LS, Krisnuhoni E. Prevalence of hepatic steatosis in chronic hepatitis B patients and its association with disease severity. Acta Med Indones. 2012; 44: 35-39.

24. Minakari M, Molaei M, Shalmani HM. Liver steatosis in patients with chronic hepatitis B infection: host and viral risk factors. Eur J Gastroenterol Hepatol. 2009; 21: 512-516. 